\title{
Ta'lim Al-Lughah Al-Arabiyah li An-Nathiqin bi Ghairiha Raqmiyan
}

$$
\text { تعليم اللغة العربية للناطقين بغيرها رقميا }
$$

Mohammed Naji ${ }^{1}$, Email: naji.casablanca@gmail.com, Jami’ah Moulay Ismael Meknes, Morocco Anas Malmous ${ }^{2}$, Email: malmousanas@gmail.com, Jami’ah Moulay Ismael Meknes, Morocco

\section{(c) (1) ()}

This is an open access article under the CC-BY-SA license

(C)2021 by the authors. Submitted for possible open access publication under the terms and conditions of the Creative Commons Attribution-ShareAlike 4.0 International License-(CC-BY-SA) (https://creativecommons.org/licenses/by-sa/4.0/)

do) DOI: http:// dx.doi.org/10.30983/ buruf.v1i1.4982

\begin{abstract}
This paper seeks to shed light on the extent to which technological applications contribute to improving and improving the process of teaching Arabic to non-native speakers, in addition to measuring the extent to which the field of teaching Arabic to non-native speakers is open to technological developments, by presenting and presenting some digital applications that can be invested in Arabic language classes. For non-native speakers, which aims to improve and renew the process of teaching Arabic to non-native speakers with distinction. Based on the foregoing, this paper stems from two main questions: 1) Has the field of teaching Arabic to non-native speakers opened up to technological development in a way that leads to its facilitation and modernization? 2) What role do digital applications and websites play in facilitating and improving the process of teaching Arabic to non-native speakers?
\end{abstract}

Keywords: Teaching Arabic to non-native speakers - modern technology - digital education educational applications.

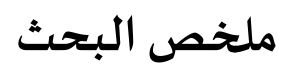

تسعى هذه الورقة إلى تسليط الضيوء على مدى إسهام التطبيقات التكنولوجية في تجويد وتحسين عملية تعليم اللغة العربية للناطقين بغيرها، علاوة على قياس مدى انفتاح مجال تعليم العربية للناطقين بغيرها على التطورات التكنولوجية، وذلك من خلال عرض وتقديم بعض التطبيقات الرقمية الممكن استثمارها في فصول تعليم اللغـة العربية للناطقين بغيرها، والتي تهدف إلى تجويد وتجديد عملية تعليم اللغة العربية للناطقين بغيرها بامتياز. بناء على ما تقدم، فإن هذه الورقة تنطلق من سؤالين أسـاسيين هما :1) هل انفتح مجال تعليم اللغة العربية للناطقين بغيرها على التطور التكنولوجي بالشكل الذي يؤدي إلى تيسيره 
وتحديثه؟ 2) وما الدور الذي تضطلع باه التطبيقات والمواقع الرقمية في تيسير وتجويد عملية تعليم اللغة العربية للناطقين بغيرها؟ الكلمات المحورية: تعليم اللغة العربية للناطقين بغيرها - التكنولوجيا الحلديثة - التعليم الرقهي - التطبيقات التعليمية.

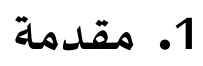

لقد مكن التطور الحاصل على مستوى الواقع الرقهي التكنولوجي فرصة لاختبار عملية

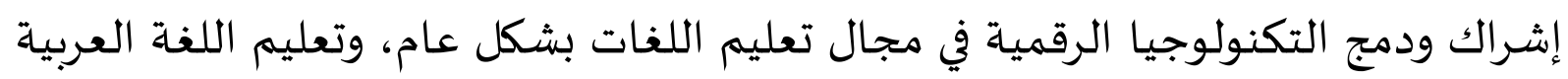

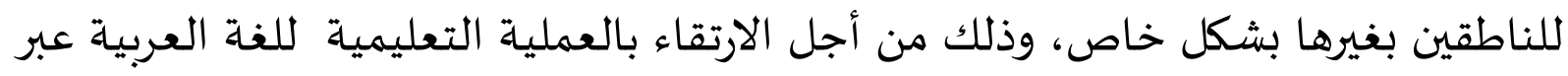
الانفتاح على الرقمياة، وذلك عبر تسخير الوسائط الرقمية من تطبيقات ومواقع إلكترونياة

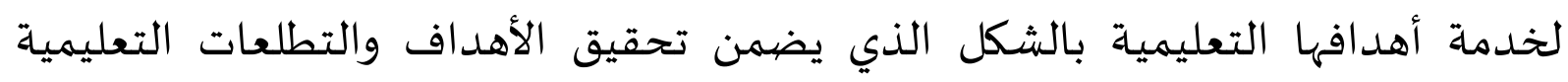
المسطرة.

ومعلوم أن الواقع التكنولوجي الرقهي يتأسس على العديد من المنصات والمواقع

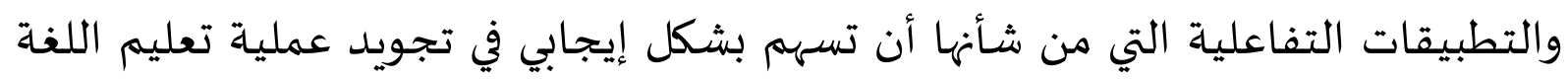
العربية للناطقين بغيرها أساسا والارتقاء بها.

وتحظى عملية دمج التكنولوجيا الرقمية في عملية تعليم اللغة العربية بأهمية بالغة لاسيما وأهها تسهم بشكل مباشر في تحديث وتجديد عملية وطرق نقل وتعليم العربية، علاوة

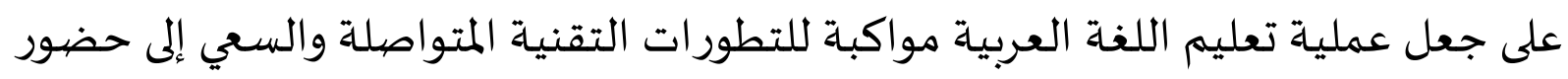
وإدخال اللغة العربية في جوهر التطبيقات والمواقع الرقمية المختلفة.

بناء على ما تقدم، فإن ورقتنا هذه ترصد الكيفية التي تتم بموجبها عملية تسخير

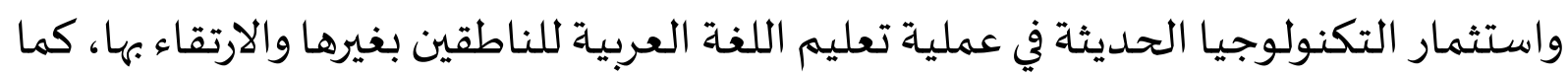
أهها تنطلق من جملة من التساؤلات المترابطة والتي يمكن إيرادها كالآتي:

أ. ما المقصود بالتعليم الرقمي للغة العربية؟

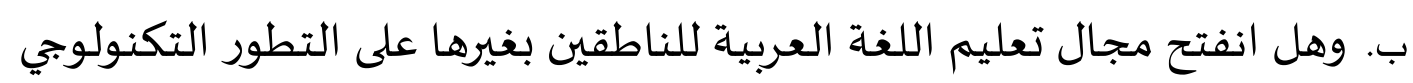
بالشكل الذي يؤدي إلى تيسيره وتحديثه 
ج. وما الدور الذي تضطلع به التطبيقات والمواقع الرقمية في تيسير وتجويد عملية تعليم اللغة العربية للناطقين بغيرها؟

ولإجابة عن هذه التساؤلات، سنشرع في خطوة أولى، بالحديث عن تعليم اللغة العربية رقميا، كما سنعمل أيضا على إبراز نجاعة توظيف الرقمية في خدمة الأهداف التعليمية للغنة

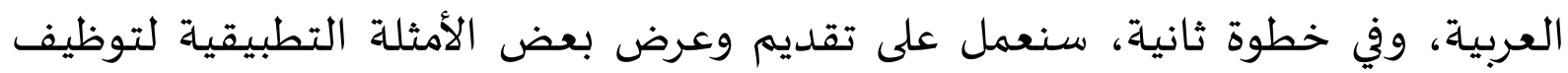
التكنولوجيا الرقمية في سيرورة تعليم اللغة العربية للناطقين بغيرها.

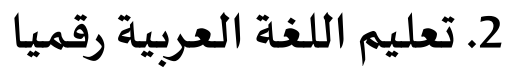

يقوم التعليم الرقمي على دمج واستثمار الوسائط الرقمية في عملية تعليم اللغات بما

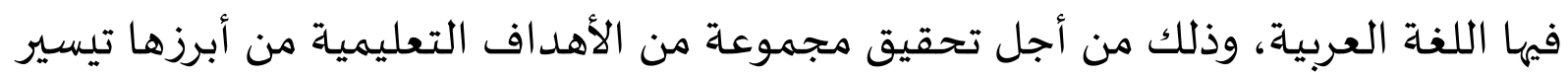

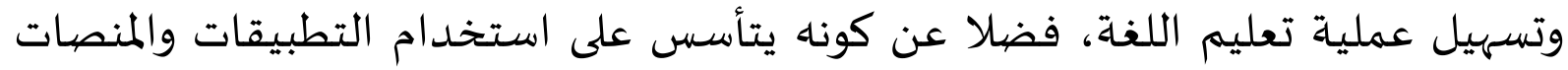

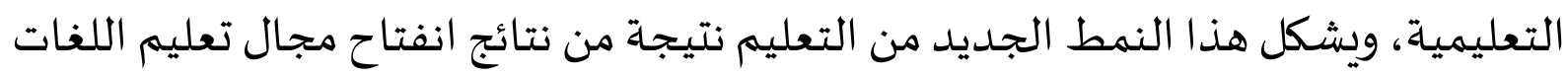
بشكل عام على التقنية وتطوراتها. وبخصوص تعليم اللغة العربية للناطقين بغيرها فلم يكن منعزلا عما يعرفه العالم من ونية

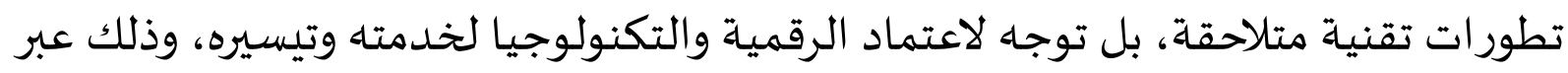

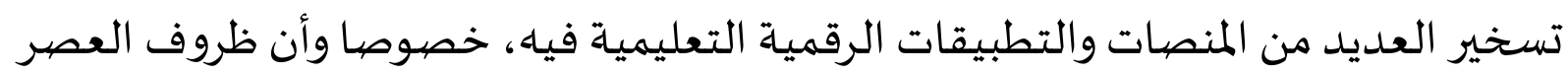
حتمت عليه ذلك وشكلت فرصة جيدة ومهمة لاختبار مدى عملية وفاعلية توظيف واستثمار

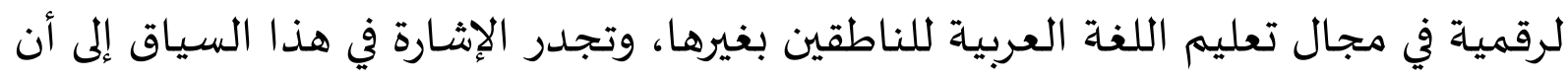

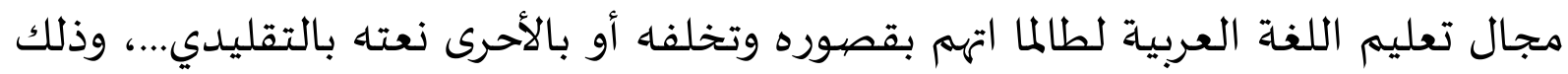

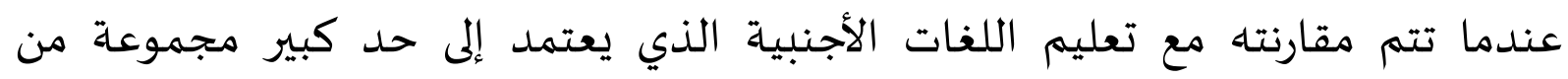
الاستراتيجيات والطرق التعليمية الحديثة والمستحدثة المعتمدة فيها.

ويصرح أنس ملموس (2021: 19) بأن التفكير في اعتماد الحاسوب وبرامجها في تعليم

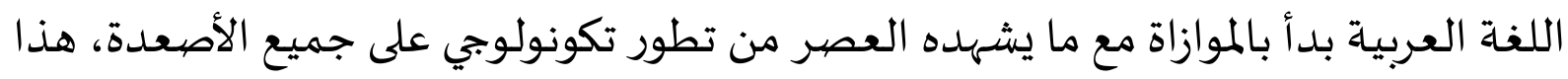

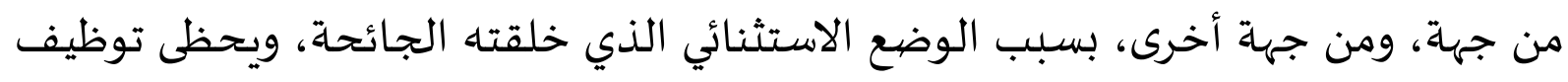

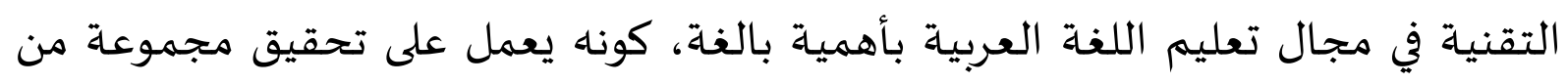

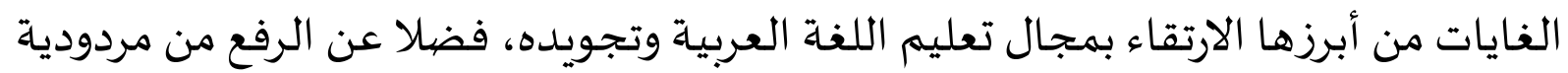


التحصيل في تعلم اللغة العربية أو بالأحرى تملكها، وأيضا في جعل المجال مواكبا لما يجري في

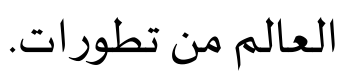

ويعرف التعليم القائم على الرقمية بالتعليم المتمازج، والذي يقوم بحسب كل من مفيد

أبو موسى وسمير الهوص (2012: 6) على منج شكل من أشكال التقنية، مثال على ذلك:

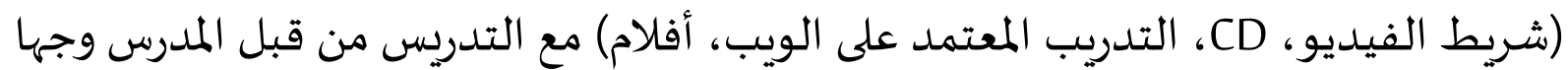

ويروم اعتماد التكنولوجيا الرقمياة في مجال تعليم اللغات عموما، وتعليم اللغة العربية

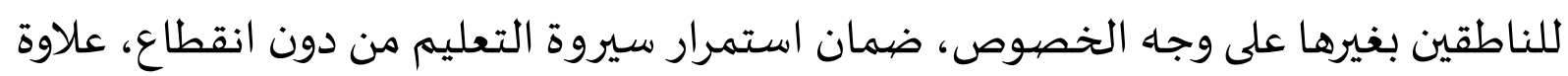

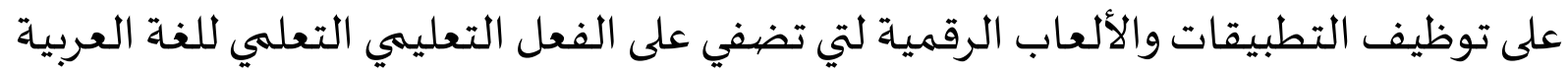

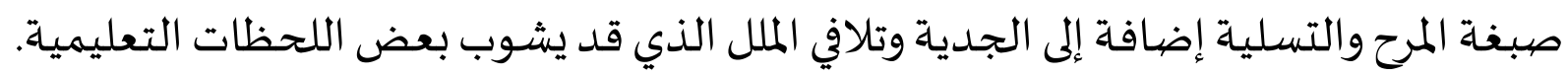

3. نجاعة توظيف الرقمية في عملية تعليم اللغة العربية

لقد أضحى التوجه نحو اعتماد الرقمية في عملية تعليم اللفات عموما، والعربية للناطقين بغيرها خصوصا، مطلبا ملحا، يرتبط في جوهره مجموعة من العوامل من أبرزها، التطورات التقنية والتكنولوجية الحاصلة في العالم، بالإضافة إلى الانفتاح المهم والكبير لى لى

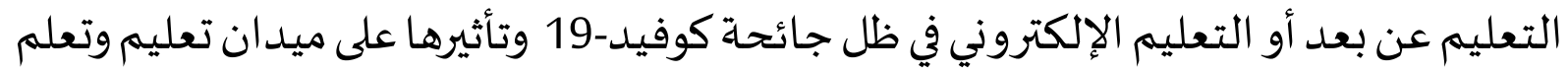

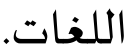

وتتمثل نجاعة وفاعلية توظيف الرقمية في عملية تعليم اللغة العربية على وجهاه الخصوص في كونها تمكن من خلق وضعيات تعليمية نشطة تمتاز بخلو المللل والروتين في تقديم المحتويات التعليمية، فضلا عن التواصل والتفاعل مع العديد من الأفراد الذين ينتمون إلى دول

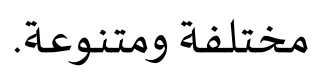

ولا شك أن عملية توظيف واستثمار التكنولوجيا في مجال تعليم اللغة العربية بالضبط

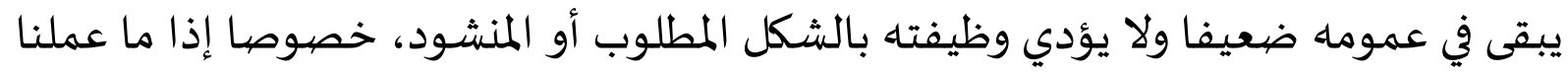
على عقد مقارنة بين توظيف التكنولوجيا في تعليم العربية من جهة، وتعليم اللغات الأجنبية

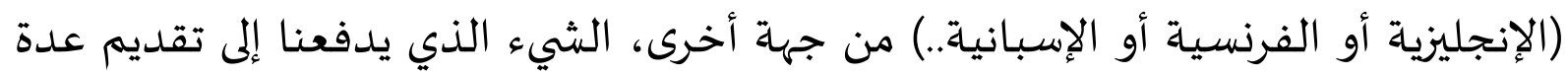


التساؤلات تتعلق أساسا بأسباب تأخر توظيف التكنولوجيا في الفصول التعليمية العربية، ومن أبرز هذه التساؤلات نذكر:

أ. هل تمتاز اللغة العربية بخصوصيات تجعلها لا تتأسس على التطبيقات

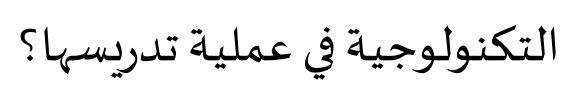

ب. أم أن الأمر يرتبط بتركيز مدرسي العربية على الأشياء النظرية والتقليدية؟

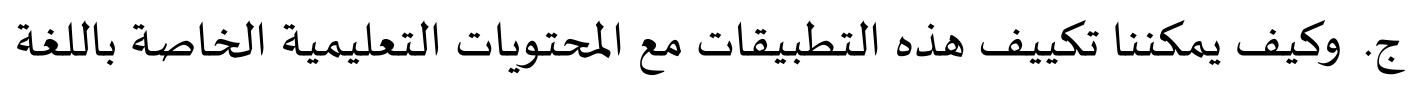

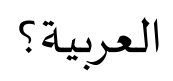

من هذا المنطلق، سنعمل أسفله على تقديم بعض التطبيقات التعليمية الإلكترونية

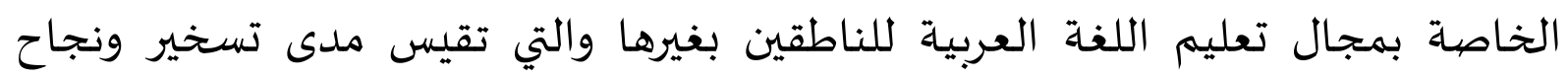

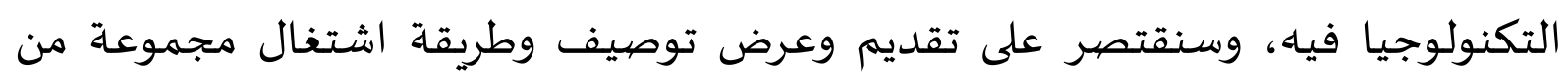
التطبيقات الرقمية التفاعلية التي يمكن توظيفها في فصول تعليم اللغة العربية للناطقين تلفين بغيرها.

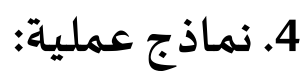

\section{Quizlet أ. تطبيق}

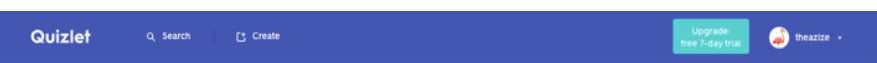

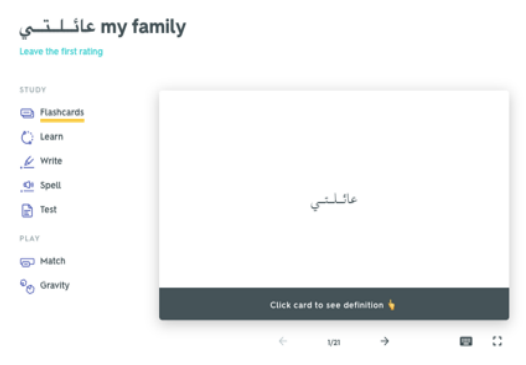

๑)-

$$
\text { - المهئة المستهدفة: المستهدفة: القراءة، الاستماع المهيع المستويات. }
$$




$$
\begin{aligned}
& \text { - - ممع وحفظ وتصنيف مفردات المعجم المدروس. } \\
& \text { - - تثبيت المعجم وترسيخها في ذهن الطالب. }
\end{aligned}
$$

\section{- المحتوى:}

- جميع مجلات ووحدات البرنامج الدراسي ( أفراد العائلة، الطعام، الألوان

والملابس...)

\section{ميزات البرنامج:}

- يتميز التطبيق بواجهة تسهل عليك استخدامه دون تعقيد والوصول إلى

$$
\text { مجموعة الدروس بسرعة. }
$$

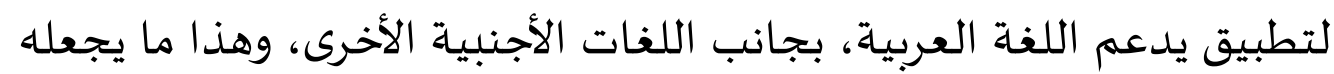
يستهدف أكبر عدد من المستفيدين والمستخدمين من كافة أنحاء العالم.

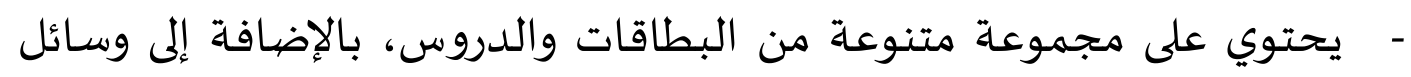

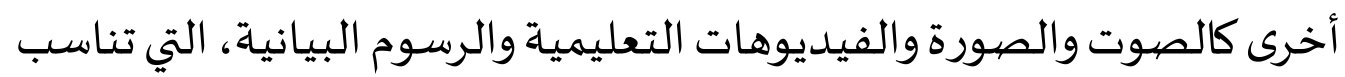

$$
\text { كل متعلم ويمكنه الاختيار من بينها بسهولة. }
$$

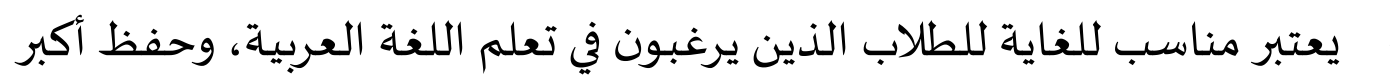

$$
\text { عدد من الكلمات مع تعلم نطقها. }
$$

- يمكنك الاستماع إلى مجموعة الأصوات ومشاهدة الفيديوهات التي قمت الفمات

$$
\text { بتسجيلها بوضيوح وبدون أي تقطيع. }
$$

- يمكنك من خلال التطبيق أن تقوم بعمل اختبار لنفسك في أي وقت، لتقييم ما

$$
\text { قمت بتعلماه. }
$$




\section{ب. تطبيق Wheel decide}
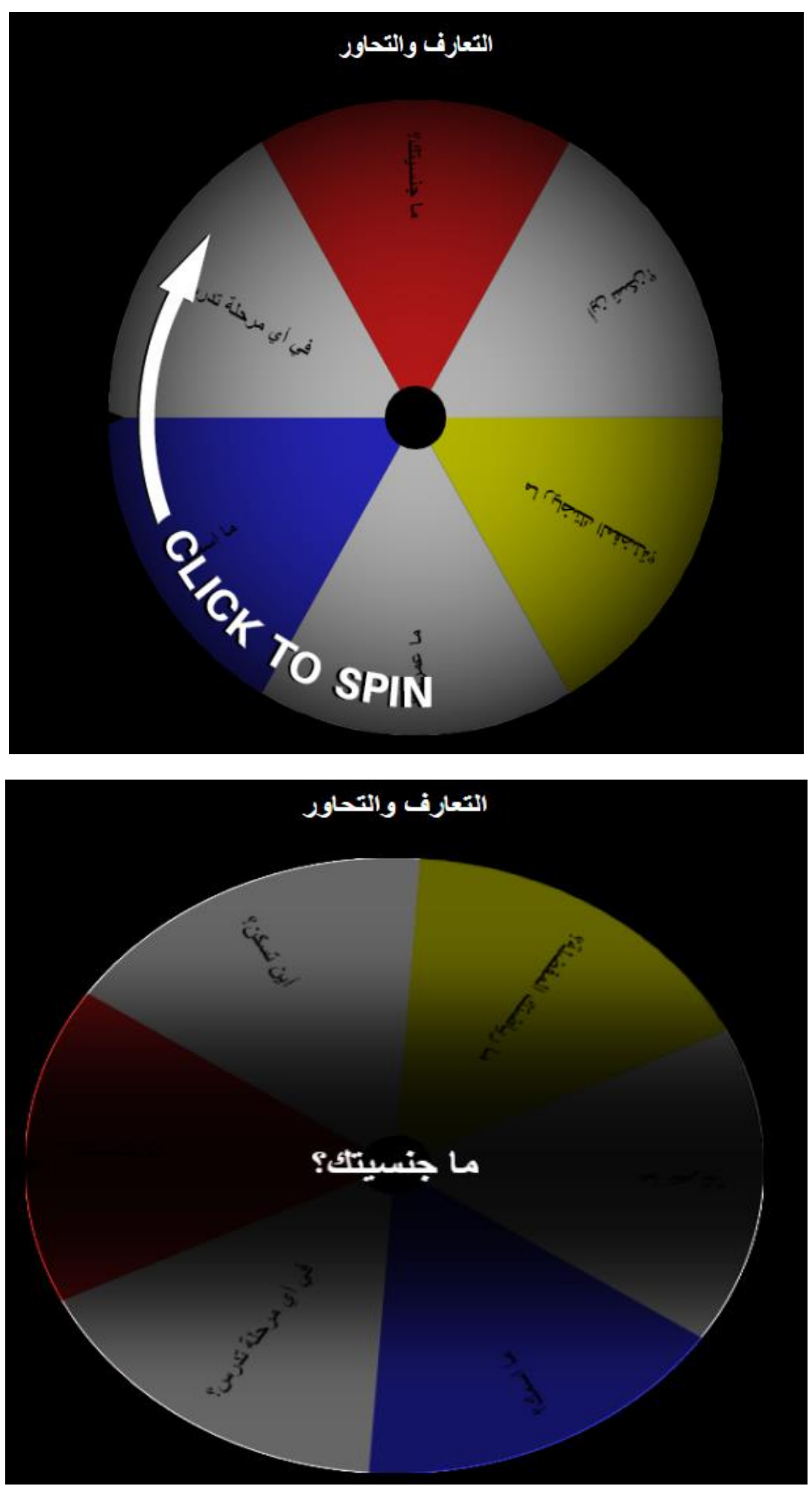


\section{- المهارة المستهدفة: المحادثة \\ - الفئة المستهدفة: جميع المستويات. \\ - الأهداف:}

- الدخول في وضعيات حوارية بناء على أسئلة اعتباطية. - - تمكين الدارس من التحدث بشكل حر بناء على اختياراته.

- المحتوى:

- - جميع مجلات ووحدات البرنامج الدراسي ( أفراد العائلة، الطعام، الألوان

والملابس....

\section{ميزات البرنامج:}

- يتميز التطبيق بواجهة تسهل عليك استخدامه دون تعقيد والوصول إلى

$$
\text { مجموعة الدروس بسرعة. }
$$

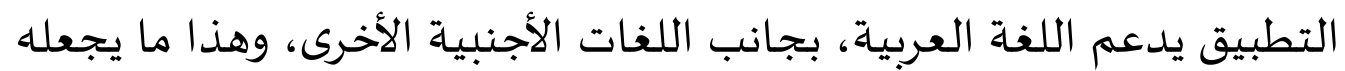

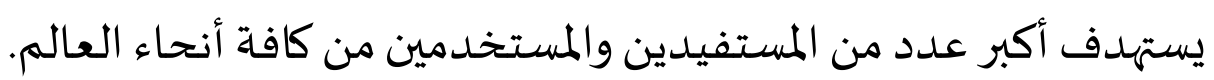

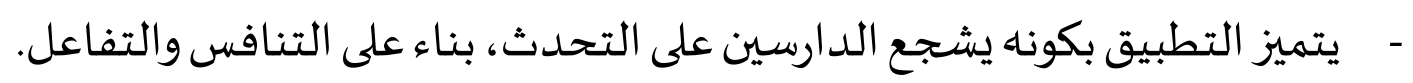

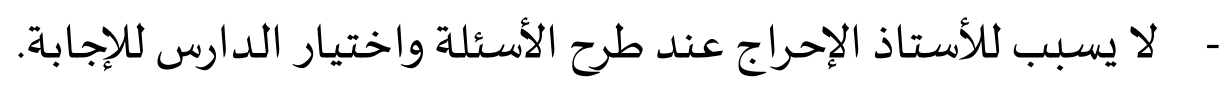

ج. تطبيق Quizziz

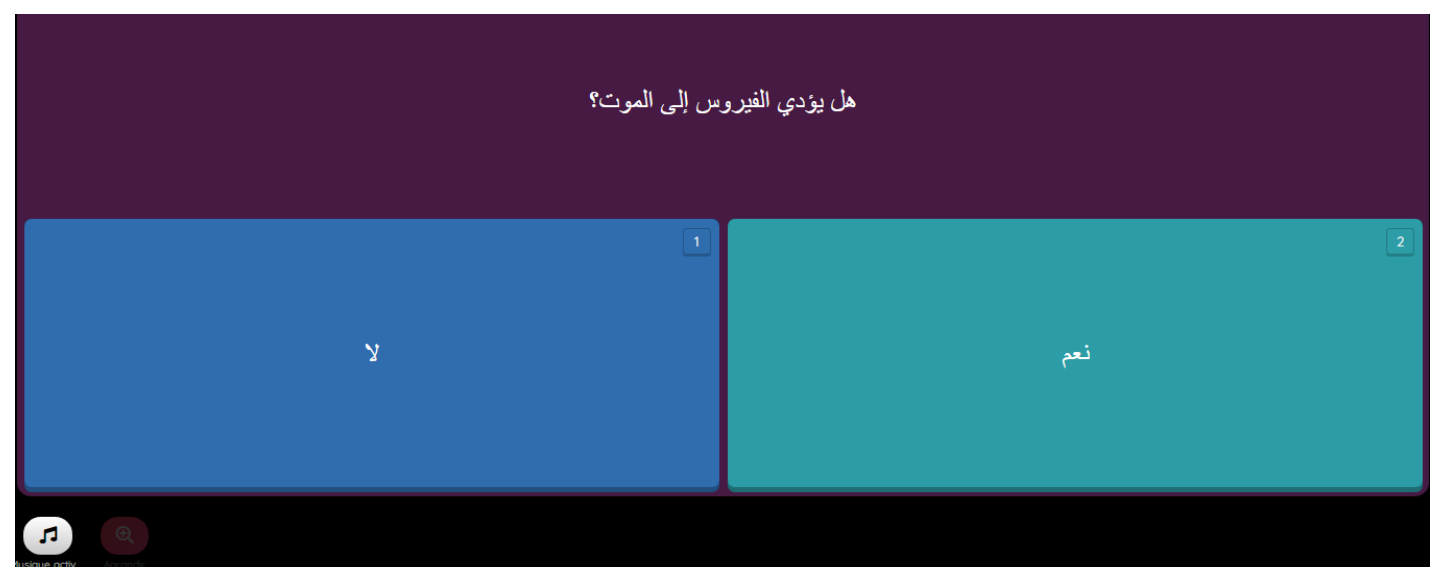



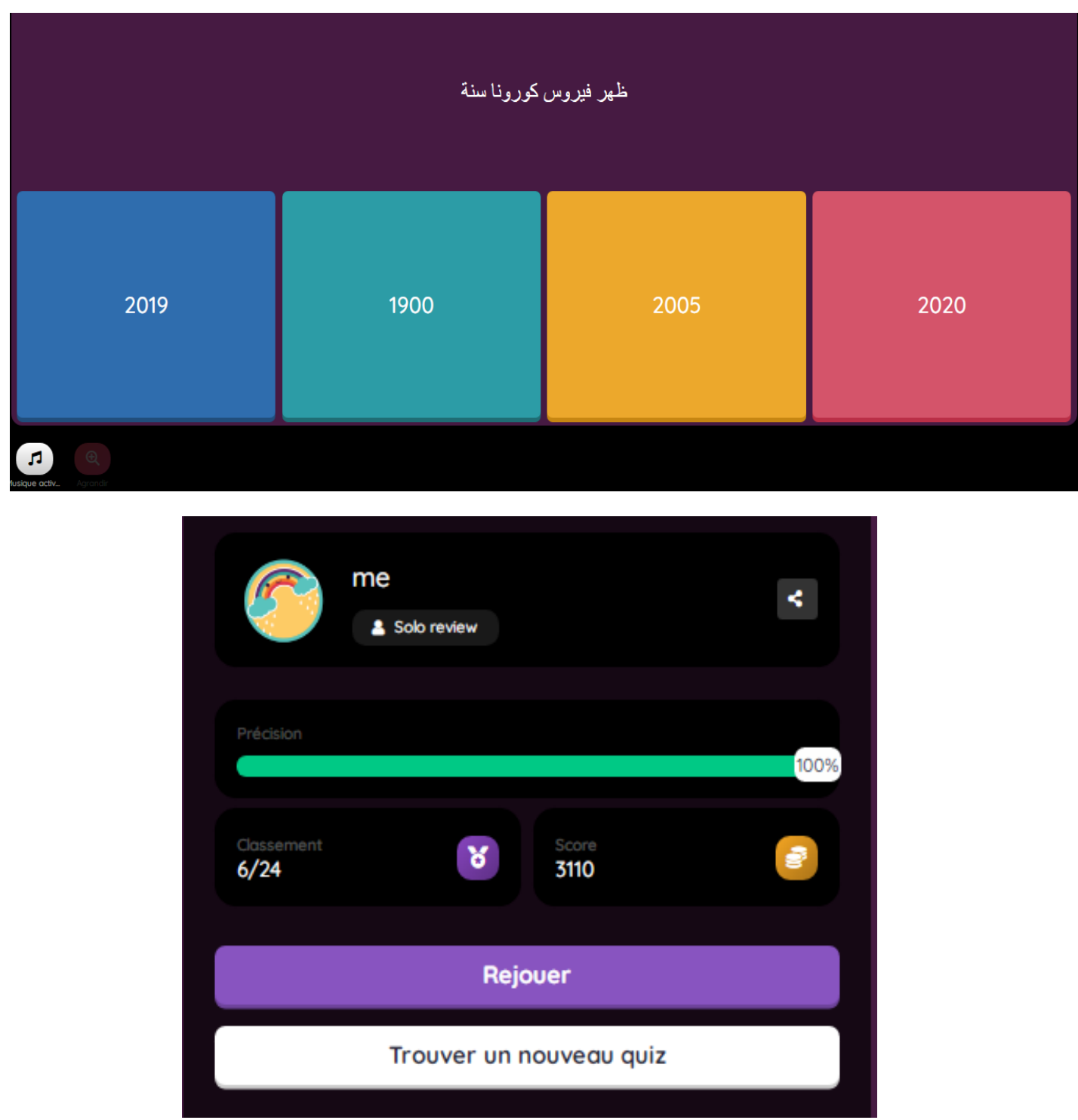

$$
\text { - المهارة المستهدفة: القراءة - الأهداف: المستهدفة: جميع المستويات. }
$$$$
\text { - - تمكين الدارس من التعلم تفاعليا بواسطة اللعب }
$$

- إضفاء الحس التفاعلي والتنافس على العملية التعليمية للغة العربية.

\section{- المحتوى:}


- - جميع مجلات ووحدات البرنامج الدراسي ( أفراد العائلة، الطعام، الألوان

والملابس...)

\section{ميزات البرنامج:}

- يتميز التطبيق بواجهة تسهل عليك استخدامه دون تعقيد والوصول إلى

$$
\text { مجموعة الدروس بسرعة. }
$$

التطبيق يدعم اللغة العربية، بجانب اللغات الأجنبية الأخرى، وهذا ما يجعله بهرعاء

يستهدف أكبر عدد من المستفيدين والمستخدمين من كافة أنحاء العالم.

- - يتميز التطبيق بكونه يشجع الدارسين على التعلم بواسطة اللعب والتسلية.

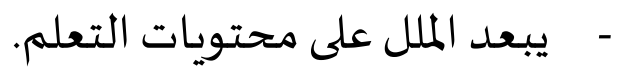

خلاصة:

لقد شكل الوضيع الحالي الذي يعتمد على التعليم الرقمي أو الإلكتروني، سببا رئيسا في

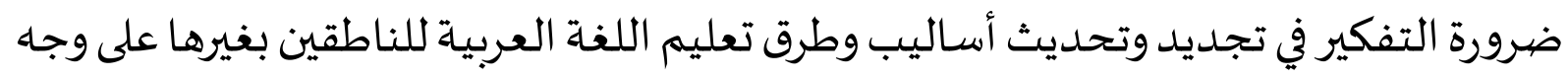

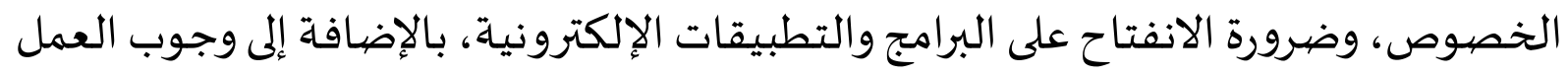

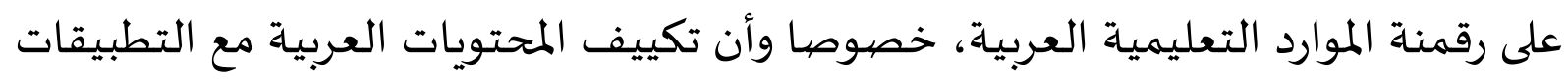

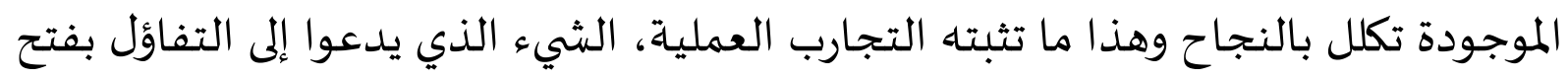

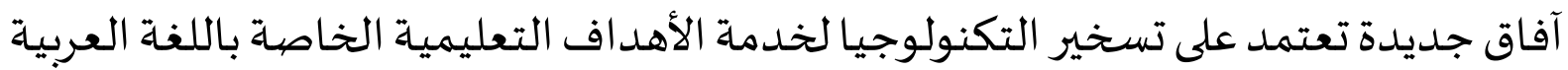
والارتقاء بها.

Mufid Ahmad Abu Musa Wa Samir Abd As-Salam Ash-Shus, (2012), At-Ta'allum Al-Mudmaj (Al-Mutamazij): Baina At-Ta'lim At-Taqlidi Wat At-Ta'lim Al-IliktruniK, AlAkadimiyun Lin-Nasyr Wat-Tauzi'. Amman, Al-Urdun

Malmus, Anas, (2021), Itstismar Baramij Al-Hasub Fi Ta'lim Al-Lughah Al-Arabiyah LinNathiqin Bighairiha, Kitab A'mal Multaqa Afdhal Al-Mumarasat Wa At-Tajarub Fi Majaal Tauzhif At-Taqniyat Fi Ta'lim Al-Lughah Al-Arabiyah 'An Bu'd, Al-Markaz At-Tarbawi Lil-Lughah Al-Arabiyah Liduwal Al-Khalij; Asy-Syariqah

https://wheeldecide.com/

https://quizlet.com/

https://quizizz.com/ 